\title{
EVALUATION OF THE CARD AGGLUTINATION TEST (CATT/T. EVANSI) IN COMPARISON WITH PCR FOR DETECTION OF TRYPANOSOMA EVANSI INFECTION IN DONKEYS IN EGYPT By
}

AHMED ABDEL-GAWAD, AHMED NASSAR and AZZA ABDEL-WAHAB*

Department of Parasitology, Faculty of Veterinary Medicine, Cairo University, P.O. Box 12211, Giza, Egypt ( ${ }^{*}$ Correspondence:dr.azza1973@yahoo.com)

\begin{abstract}
This study was initiated to evaluated CATT test in comparison with PCR for detection of Trypanosoma evansi infection in donkeys in Egypt. Six donkeys free from T. evansi were inoculated with $T$. evansi strain (Egypt CD2) which had been isolated from naturally infected horse. Parasitological examination of the donkeys revealed a prepatent period of T. evansi 14 DPI. Two blood samples (heparinized and plain) were taken from each donkey every 4 days starting from day 0 until the end of the experiment for serological examination (CATT/ T. evansi). Body temperature was also estimated. Serological examination of the experimentally inoculated donkeys' no.1, 2, 4 and 5 showed that seroconversion occurred on 12 DPI and remained until death of animals. Other experiment, blood samples from 416 donkeys collected randomly from different governorates of Egypt, they were tested parasitologically (stained blood smear, mice inoculation (MI) and microhaematocrit centrifugation technique (MHCT) and serologically by using CATT/ T. evansi for diagnosis T. evansi infection. From the previous animals, 26 parasitologically negative donkeys were used for comparison between the results obtained by CATT/T. evansi \& PCR techniques. Of 26 parasitologically negative samples, $9(34.6 \%) \& 14(53.85 \%)$ samples were found positive by using CATT and PCR techniques respectively. Despite of the simplicity and low-coast of CATT test, it is recommended to use it in combination with PCR technique for accurate and reliable results.
\end{abstract}

Key words: CATT, donkeys, experimental infection, PCR.

\section{Introduction}

Trypanosoma evansi causes a fatal animal loss mainly among camel cattle, horses, donkeys, zebra, mules, dogs and pigs can be infected (Dia et al, 1997; O.I.E., 2004). Trypanosomosis is widely distributed sickness outside the Tse Tse belt in Africa. T. evansi in horse induces acute and chronic clinical symptoms in the diseased animals which last up to 3 months to 3 years. However, some infected horses did not show symptoms (Desquesnes et al, 2013).

Serological techniques like direct agglutination test (CATT/T. evansi) based on RoTat 1.2 VSG and ELISA/T. evansi and molecular tests like PCR are used as specific diagnostic tools for surra and have been underwent in various studies in different hosts and countries (Gutierrez et al, 2000; Verloo et al, 2000). CATT/T. evansi is considered to be a well-validated field test (Claes et al, 2004).

This study aimed to evaluate card aggluti- nation test (CATT/ T. evansi) for detection of antibodies against Trypanosoma evansi (T. evansi) in experimentally and naturally infected donkeys in comparison with molecular study.

\section{Material and methods:}

Experimental infection: Six donkeys (one year old) free from $T$. evansi after parasitological (buffy coat technique (BCT), mouse inoculation and serological examination (CATT/ T. evansi) were assigned into experimental (no. 1, 2, 3, 4 \& 5) and control (no.6) groups. All were parasite-free ones.

Trypanosoma evansi strain (Egypt CD2) was isolated from Egyptian naturally infected horse. Donkeys (1, 2, 3, 4 \& 5) were each intravenously inoculated with 350.000 , $500.000,250.000,50.000 \& 100.000$ trypanosomes/donkey respectively. Two blood samples (heparinized \& plain, $5 \mathrm{ml}$ each) were taken from each donkey every 4 days starting from day 0 until 50 days post-inoculation (DPI). Body temperature and clinical 
symptoms were recorded daily for each one.

Sera were tested by card agglutination test (Fig. 1, CATT / T. evansi). Blood samples of 416 donkeys obtained from different Egyptian governorates from March 2016 to February 2017. Samples were tested parasitologically (stained blood smears, buffy coat technique (BCT), mouse inoculation (MI) or serologically by CATT/T. evansi.

Serological examination by CATT/ T. evansi: Sera of the animals were prepared by two fold serial dilutions (1:4-1:128) with the supplied buffer for testing in CATT /T. $e v$ ansi (Bajyana Songa and Hamers, 1988). Sample was considered positive when blue granular agglutination was appeared at dilution 1:4. End point titer was determined for the sera of infected animals by testing higher dilution (Verloo et al, 2000).

Molecular technique (PCR): Twenty six parasitologically negative donkey samples were examined by molecular technique (PCR) in comparison with CATT / T. evansi which was performed on the same samples. Genomic DNA was extracted from these 26 donkeys frozen whole blood samples. Samples were thawed then centrifuged at $3000 \mathrm{rpm} / 5 \mathrm{~min}$ at $4^{\circ} \mathrm{C}$. Sediment was collected. The DNA extraction was done (Ijaz et al, 1998). The mixture was subjected to 40 cycles of amplification in the thermocycler (PTC 100mj Research USA). Amplified products were electrophoresis analyzed in $1.5 \%$ agarose gel and UV illumination after ethidium bromide staining of tDNA. Specific DNA fragment of T. evansi was amplified of size 164 base pair (bp) (Ijaz et al, 1998).

Ethics: All investigations reported in the study were approved by the institutional animal use protocol committee of Cairo University, Egypt.

\section{Results}

Parasitological examination of the infected donkeys with $T$. evansi revealed a prepatent period of $T$. evansi 1-4 DPI with a patent period varied from 7 to 50 DPI (Tab. 1).

The body temperature of five experimentally infected donkeys was normal $\left(37.5-38.5^{\circ} \mathrm{C}\right)$ during the first two days (donkey no. $1,4 \&$ 5 ) or 3 days (donkey no. 2). The first peak of pyrexia $\left(40^{\circ} \mathrm{C}\right)$ was continued $1-2$ days PI, and a second one $\left(39-40.1^{\circ} \mathrm{C}\right)$ was estimated for 2-5days. Body temperature showed no significant increase until the end of experiment on $50^{\text {th }}$ DPI. Body temperature of donkey no. 3 was normal from $1^{\text {st }}$ DPI until its death $8^{\text {th }}$ DPI. Body temperature of negative control donkey (no.6) remained normal and it didn't show any clinical symptoms throughout the experimental period (50DPI).

Lacrimation from both eyes appeared in all inoculated donkeys on $3^{\text {rd }}$ DPI and continued until the experimental end (50 DPI). This eye discharge was watery in nature then it changed into mucoid one and it collected at internal eye canthus. Alopecia recorded after $15^{\text {th }}$ DPI and continued until experimental end. Vulver discharge was seen in donkeys' no. 2 and 4 on days 32 PI \& 4PI respectively. This discharge continued till death of animals. Emaciation was began in appearance on the $10^{\text {th }}$ DPI and continued till death of animals. All experimentally inoculated animal were reluctant to walk, dull and depressed, paresis of hind limbs then complete paralysis were in donkeys no. 2, 4 $\& 5$ one or two days prior to animal death.

T. evansi was diagnosed from donkey no. 1 , 2, 3, 4 \& 5 until 50, 28, 7, 40 \& 36 DPI respectively. Donkeys nos. 1 \& 6 survived until experimental end while the other donkeys died on 28, 8, 40 \& 36 DPI (Tab. 2).

Serological examination of the experimentally inoculated donkeys nos.1, 2, 4 \& 5 showed that seroconversion occurred on 12 DPI (end-titer 1:32), 8(1:8), 4(1:8), 16(1:4) respectively and remained until death of the inoculated ones. Maximum end point titer recorded in donkey no.1 was 1:32. Donkey no. 3 died on $8^{\text {th }}$ DPI before seroconversion report. Donkey (control) remained normal.

Natural infection: The 416 donkeys from different governorates of Egypt which were found negative parasitologically revealed positive results by using CATT/T. evansi revealed $63(15.12 \%)$ donkeys positive at 
dilution of 1:4.

Comparison between CATT and PCR: Out of 26 parasitologically negative samples, 9
(34.6\%) and $14(53.85 \%)$ samples were positive by using CATT and PCR technique respectively (Tab. 3).

Table 1: Details PCR mixture of 50 $\mu$ l volume, primers and amplification conditions used in PCR technique.

\begin{tabular}{|c|c|c|}
\hline PCR mixture $(50 \mu 1)$ & Primers (TBR1 \&TBR2) $\left(5^{`}-3^{`}\right)$ & PCR condition for each cycle \\
\hline $\begin{array}{l}\text { DNA template }(1 \mu 1) \\
\text { Primer } 1(\mathrm{TBR} 1 ; 0.5 \mu 1) \\
\text { Primer } 2(\mathrm{TBR} 2 ; 0.5 \mu 1) \\
\text { PCR buffer }(5 \mu 1) \\
\text { DNTP }(2 \mu 1) \\
\text { DNA polymerase }(1 \mu 1) \\
\text { Dist. Water }(40 \mu 1), 30 \mu 1 \text { mineral oil added } \\
\text { to each sample. }\end{array}$ & $\begin{array}{l}\text { F:5-GAATAT TAA ACA ATG } \\
\text { CGC AG-3 } \\
\text { R: 5`-CCA TTT ATT AGC } \\
\text { GTT GC-3 }\end{array}$ & $\begin{array}{l}\text { Denaturation at } 94^{\circ} \mathrm{C} \text { for } 1 \mathrm{~min} \\
\text { Annealing at } 55^{\circ} \mathrm{C} \text { for } 75 \mathrm{sec} \text {. } \\
\text { Extension at } 72^{\circ} \mathrm{C} \text { for } 1.5 \mathrm{~min} \text {. } \\
\text { Prior to cycling mixture subjected to } 94^{\circ} \mathrm{C} \\
\text { incubation for } 4 \mathrm{~min} \text {. } \\
\text { Extension of last cycle at } 72^{\circ} \mathrm{C} \text { for } 10 \mathrm{~min} \text {. }\end{array}$ \\
\hline
\end{tabular}
to each sample.

Table 2: Donkeys experimentally infected with T. evansi.

\begin{tabular}{|c|c|c|c|c|c|}
\hline $\begin{array}{c}\text { Donkey } \\
\text { No. }\end{array}$ & $\begin{array}{c}\text { Infective } \\
\text { dose }\end{array}$ & $\begin{array}{c}\text { Prepatent period } \\
\text { (days) }\end{array}$ & $\begin{array}{c}\text { Duration of parasi- } \\
\text { taemia (days) }\end{array}$ & seroconversion DPI & $\begin{array}{c}\text { Death after (days) } \\
\text { inoculation (DPI) }\end{array}$ \\
\hline 1 & 350.000 & One & 50 & 12 & 50 \\
\hline 2 & 500.000 & 3 & 26 & 8 & 28 \\
\hline 3 & 250.000 & 3 & 7 & none & 8 \\
\hline 4 & 50.000 & 2 & 40 & 4 & 40 \\
\hline 5 & 100.000 & 4 & 36 & 16 & 36 \\
\hline
\end{tabular}

Table 3: Comparison of 26 parasitologically negative donkeys by PCR and CATT/ T. evansi

\begin{tabular}{|c|c|c|c|}
\hline No. of Donkeys & Serological using CATT & Parasitological (mice inoculation) & Positive by PCR \\
\hline 9 & $+\mathrm{ve}$ & $-\mathrm{ve}$ & 9 \\
\hline 9 & $\pm \mathrm{ve}$ & $-\mathrm{ve}$ & 3 \\
\hline 8 & $-\mathrm{ve}$ & $-\mathrm{ve}$ & 2 \\
\hline
\end{tabular}

\section{Discussion}

The experimental infection proved that $T$. evansi strain from naturally infected horse was infectious for donkeys. A prepatent period was1-4 DPI in experimentally infected donkeys. T. evansi specific antibodies were estimated with high titer using CATT on $12^{\text {th }}$ DPI (end-titer $\left.1: 32\right), 8^{\text {th }}(1: 8), 4^{\text {th }}(1: 8)$ $\& 16^{\text {th }}(1: 4)$ in inoculated donkeys no. $1,2,4$ $\& 5$ respectively.

CATT/ T. evansi was compared with PCR for diagnosis of $T$. evansi among 26 parasitologically negative donkeys. Nine donkeys were positive and 9 doubtful but, PCR was 14 positive (9 CATT+ve, $3 \mathrm{CATT} \pm \mathrm{ve}, \& 2$ CATT-ve). Five PCR positive samples were 3 CATT \pm ve, 2 CATT-ve. Serological test was unable to distinguish between active infections and cured one, but PCR provided a definite tool to assess therapy effectiveness and disease progression (Clausen et al, 1999; Tehseen et al, 2017).

The seropositive but parasitologically negative animals must be confirmed by CATT/ T. evansi performances by PCR test (TBR primers) which proved to be accurate test
(Desquesnes and Davila, 2002). This agreed with Magnus (1988) who found that CATT test was highly sensitive but not strictly species-specific, and recommended to use CATT \& PCR for reliable diagnosis.

The 416 donkeys were negative parasitologically while serological examination revealed $63(15.12 \%)$ donkeys positive at dilution of 1:4. The value obtained in the present study disagreed with Hilali et al. (1998) who reported $41(82 \%)$ donkeys had antibodies against $T$. evansi using CATT. This difference may be due to low of examined animals (50 donkeys) by these authors.

The absence of parasitologically positive donkeys might be attributed to parasite occurence in early period after infection but persistence of antibodies against Trypanosoma sp. for long time even after treatment increased probability of serological techniques detection (Luckins et al, 1979). In routine Surra surveys, CATT/T. evansi proved validated test, and overestimated antibodies persisted for several months (Desquesnes and Davila, 2002). 


\section{Dedication}

This paper is dedicated to the spirit of the late Professor Dr. Mossad Hilali.

\section{References}

Bajyana Songa, E, Hamers, R, 1988: A card agglutination test (CATT) for veterinary use based on early RoTat $1 / 2$ for Trypanosoma evansi. Ann. Soc. Belg. Med. Trop. 68:233-40

Claes, F, Radwanska, M, Urakawa, T, Majiwa, P, Goddeeris, B, et al, 2004: Variable surface glycoprotein RoTat 1.2 PCR as a specific diagnostic tool for the detection of Trypanosoma evansi infections. Kinetoplastid Biol. Dis. 3:3-8. Clausen, P, Gebreselassie, G, Abditcho, S, Mehlitz, D, Staak, C, 1999: Detection of trypanosome DNA in serologically positive but a parasitaemic horses of dourine in Ethiopia. Tokai J. Exp. Clin. Med. 23, 6:303-8.

Desquesnes, M, Davila, AMR, 2002: Applications of PCR-based tools for detection and identification of animal trypanosomes: A review and perspectives. Vet. Parasitol. 109:213-31.

Desquesnes, M, Holzmuller, P, De-Hua, L, Dargantes, A, Zhao-Rong, L, et al, 2013: Trypanosoma evansi and Surra: A review and perspectives on origin, history, distribution, taxonomy, morphology, hosts, and pathogenic effects. Biomed. Res. Art. ID, 194176, 22 pages. Dia, ML, Dip, C, Manitou, M, Jacquie, P, Thai, A, 1997: Some factors affecting the prevalence of Trypanosoma evansi in camels in Mauritania. Vet. Parasitol. 72:111-20.

Gutierrez, C, Just, MC, Cerebra, JA, Magn-

Gutierrez, C, Just, MC, Cerebra, JA, Magnus, E, Verloo, D, et al, 2000: Camel trypanosomosis in the Canary Islands: assessment of and infection rates using the card agglutination test
(CATT/T. evansi) and parasite detection tests. Vet. Parasitol. 90:155-9.

Hilali, M, El Said, HM, Zayed, A, El Gayash, A, Meirvenne, MV, 1998: Seroprevalence of Trypanosoma evansi antibodies in some domestic animals in Egypt. RCPMI-Obihiro, Japan/ O.I.E. Int. Symp.19-22 August; Strategies for Res. \& Contof Surra (Trypanosoma evansi).

Ijaz, MK, Nur, E, Kamal, MSA, Mohamed, A IA, Dar, FK, 1998: Comparative studies on sensitivity of polymerase chain reaction and microscopic examination for the detection of Trypanosoma evansi in experimentally infected mice. Comp. Immunol. Microbiol. Infect. Dis. 21:21523.

Luckins, AG, Boid, R, Rate, P, Mahmud, M M, Al Malik, KH, et al, 1979: Serodiagnosis of infections with Trypanosoma evansi in camels in Sudan. Trop. Anim. Hlth. Prod. 11:1-12.

Magnus, E, 1988: Contribution à la standardisation du test d'immunofluorescence pour le serodiagnostic de la milady du sommeil à Trypanosoma brucei gambiense. Rev. Assoc. Belge. Tech. Lab. 15, 321-343.

OIE, 2004: (Office International des Epizootes) Manual of diagnostic tests and vaccines for terrestrial animals [online]. Paris: OIE; Trypanosoma evansi infections (including Surra).

Tehseen, S, Jahan, N, Desquesnes, M, Shahzad, MI, Qamar, MF, 2017: Field investigation of Try-panosoma evansi and comparative analysis of diagnostic tests in horses from Bahawalpur, Pakistan. Turk. J. Vet. Anim. Sci. 41:288-93. Verloo, D, Holland, W, My, LN, Thanh, NG, Tam, PT, et al, 2000: Comparison of serological tests for Trypanosoma evansi natural infections in water buffaloes from North Vietnam. Vet. Parasitol. 92:87-96.

\section{Explanation of figure}

Fig. 1: Positive and negative sera examined by CATT. Grades 1-3: +++ve, Grades 4-5: ++ve, Grades 6-7: +ve, Grade 8: \pm ve \& Grades 9-10: -ve

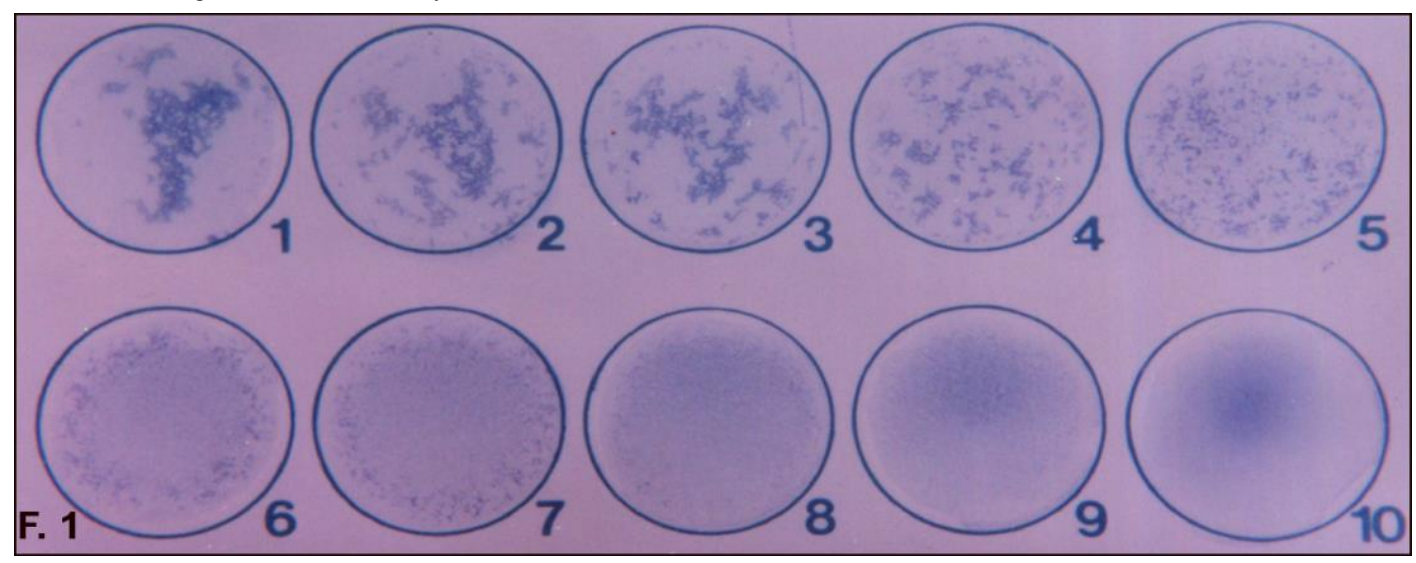

